\title{
Effect of reducing milk production using a prolactin-release inhibitor or a glucocorticoid on metabolism and immune functions in cows subjected to acute nutritional stress
}

\author{
S. Ollier, ${ }^{*}$ F. Beaudoin, ${ }^{*}$ N. Vanacker, ${ }^{*} \dagger$ and P. Lacasse ${ }^{* 1}$ \\ *Sherbrooke Research and Development Centre, Agriculture and Agri-Food Canada, Sherbrooke, QC, Canada J1M 0C8 \\ †Département de biologie, Faculté des sciences, Université de Sherbrooke, Sherbrooke, QC, Canada J1K 2R1
}

\begin{abstract}
When cows are unable to consume enough feed to support milk production, they often fall into severe negative energy balance. This leads to a weakened immune system and increases their susceptibility to infectious diseases. Reducing the milk production of cows subjected to acute nutritional stress decreases their energy deficit. The aim of this study was to compare the effects on metabolism and immune function of reducing milk production using quinagolide (a prolactin-release inhibitor) or dexamethasone in feed-restricted cows. A total of 23 cows in early/mid-lactation were fed for $5 \mathrm{~d}$ at $55.9 \%$ of their previous dry matter intake to subject them to acute nutritional stress. After $1 \mathrm{~d}$ of feed restriction and for $4 \mathrm{~d}$ afterward (d 2 to 5), cows received twice-daily i.m. injections of water (control group; $\mathrm{n}$ $=8$ ), $2 \mathrm{mg}$ of quinagolide (QN group; $\mathrm{n}=7$ ), or water after a first injection of $20 \mathrm{mg}$ of dexamethasone (DEX group; $\mathrm{n}=8$ ). Feed restriction decreased milk production, but the decrease was greater in the QN and DEX cows than in the control cows on d 2 and 3. As expected, feed restriction reduced the energy balance, but the reduction was lower in the QN cows than in the control cows. Feed restriction decreased plasma glucose concentration and increased plasma nonesterified fatty acid (NEFA) and $\beta$-hydroxybutyrate (BHB) concentrations. The QN cows had higher glucose concentration and lower BHB concentration than the control cows. The NEFA concentration was also lower in the QN cows than in the control cows on d 2. Dexamethasone injection induced transient hyperglycemia concomitant with a reduction in milk lactose concentration; it also decreased BHB concentration and decreased NEFA initially but increased it later. Feed restriction and quinagolide injections did not affect the blood concentration
\end{abstract}

Received July 6, 2016.

Accepted September 2, 2016.

${ }^{1}$ Corresponding author: Pierre.Lacasse@agr.gc.ca or activity of polymorphonuclear leukocytes (PMN), whereas dexamethasone injection increased PMN blood concentration but decreased the proportion of PMN capable of inducing oxidative burst. Incubation of peripheral blood mononuclear cells in serum harvested on $\mathrm{d} 2$ of the restriction period reduced their ability to react to mitogen-induced proliferation, and injection of quinagolide or dexamethasone could not alleviate this effect. This experiment shows that prolactin-release inhibition could be an alternative to dexamethasone for reducing milk production and energy deficit in cows under acute nutritional stress, without disturbing immune function. Key words: quinagolide, dexamethasone, negative energy balance, dairy cow

\section{INTRODUCTION}

In a number of situations, including surgery, inability to stand up, milk fever, and ketosis, cows may be unable to eat enough to support milk production. Consequently, high-yielding cows fall into severe negative energy balance and must mobilize body reserves extensively to balance the deficit between nutrient intake and the nutrients required for milk production. Cows in an energy deficit have a weakened immune system, which increases their susceptibility to infectious diseases such as mastitis and metritis (Suriyasathaporn et al., 2000; Sheldon, 2004; Goff, 2006). Indeed, blood nonesterified fatty acid (NEFA) and BHB concentrations increase when cows are in negative energy balance, and glucose concentration decreases (Chilliard et al., 1998); these changes in metabolite concentrations may affect the immune functions of leukocytes (reviewed in Ingvartsen and Moyes, 2013). Therefore, strategies that improve energy status may limit immunosuppression in cows subjected to acute nutritional stress.

Reducing the milk production of cows under acute nutritional stress decreases their energy deficit. Glucocorticoids such as dexamethasone are used to treat disorders such as ketosis, mastitis, respiratory tract diseases, udder edema, and musculoskeletal inflamma- 
tion. Large doses of glucocorticoids inhibit milk synthesis (Braun et al., 1970; van der Kolk, 1990) and are sometimes used to temporarily reduce milk production in cows under acute nutritional stress. However, glucocorticoids are potent immunosuppressants and increase the risk of infection (Roth and Kaeberle, 1982). Recent studies by our team have shown that quinagolide, a potent and specific inhibitor of prolactin (PRL), can also reduce milk production in lactating cows (Lacasse et al., 2011) without causing metabolic disturbance or immunosuppression (Ollier et al., 2014). These findings suggest that an inhibition of the lactogenic signal via PRL could be used to temporarily decrease milk production in lactating cows at high risk of becoming ill. The aim of the present study was to compare the effects on metabolism and immune function of reducing milk production using quinagolide or dexamethasone in feed-restricted cows.

\section{MATERIALS AND METHODS}

\section{Animals and Experimental Design}

This experiment was conducted in accordance with the guidelines of the Canadian Council on Animal Care (1993). Twenty-three multiparous Holstein cows (99 \pm 4 DIM) were housed in individual tie stalls at Agriculture and Agri-Food Canada's Sherbrooke Research and Development Centre (Sherbrooke, QC, Canada). All the cows were subjected to acute nutritional stress by severely restricting their feed for $5 \mathrm{~d}$. They were fed at $55.9 \pm 0.4 \%$ of their DMI of the previous week. After $1 \mathrm{~d}$ of feed restriction and for the remainder of the feed-restriction period, the cows were assigned to 1 of 3 groups as follows: the control group $(\mathrm{n}=8)$ received twice-daily i.m. injections of water (B. Braun Medical Inc., Scarborough, ON, Canada), the quinagolide group ( $\mathrm{QN}$ group; $\mathrm{n}=7$ ) received twice-daily i.m. injections of $2 \mathrm{mg}$ of quinagolide (Ferring, Wallisellen, Switzerland), and the dexamethasone group (DEX group; $\mathrm{n}=8$ ) received the same water injections as the control cows after an initial injection of $20 \mathrm{mg}$ of dexamethasone sodium phosphate (Vétoquinol N.A. Inc., Lavaltrie, QC, Canada). To facilitate experiment management, 2 blocks of cows were studied separately: the first block consisted of 4 control, $3 \mathrm{QN}$, and 4 DEX cows, and the second block consisted of 4 control, 4 QN, and 4 DEX cows. Before, during, and after the feed-restriction period, all animals were fed a TMR containing (on a DM basis) $36.6 \%$ grass silage, $24.4 \%$ corn silage, $18.7 \%$ corn grain, $10.6 \%$ soybean meal, $1.8 \%$ beet pulp, $3.0 \%$ chopped dry hay, $3.2 \%$ non-mineral supplement, and $1.7 \%$ mineral supplement. The composition of the TMR is presented in Table 1. Feed intake was recorded daily
Table 1. Composition of the diet (\% of DM unless otherwise noted)

\begin{tabular}{lc}
\hline Chemical composition & Value \\
\hline $\mathrm{CP}$ & $18.3 \pm 0.2$ \\
$\mathrm{ADF}$ & $22.1 \pm 0.6$ \\
$\mathrm{NDF}$ & $33.1 \pm 1.2$ \\
$\mathrm{P}$ & $0.43 \pm 0.01$ \\
$\mathrm{~K}$ & $1.85 \pm 0.04$ \\
$\mathrm{Ca}$ & $0.89 \pm 0.03$ \\
$\mathrm{NE}$ & $(\mathrm{Mcal} / \mathrm{kg}$ of $\mathrm{DM})$ \\
\hline
\end{tabular}

for each cow from $10 \mathrm{~d}$ before feed restriction until $20 \mathrm{~d}$ after, and each cow's BW was determined at the start and end of the experiment.

\section{Milk Collection and Energy Balance}

The cows were milked twice daily, and milk yield was recorded at each milking from $15 \mathrm{~d}$ before feed restriction until $20 \mathrm{~d}$ after. Milk samples were collected at the a.m. milking on $\mathrm{d}-6,-2,-1,1$ (after $1 \mathrm{~d}$ of feed restriction), 2 (after $1 \mathrm{~d}$ of injections), 3, 4, 5, 6, 12, and 19. Milk fat, protein, lactose, and BHB concentrations and SCC were determined in a commercial laboratory (Valacta Inc., Ste-Anne-de-Bellevue, QC, Canada). Energy balance was estimated as the difference between energy consumed and the sum of energy required for maintenance and milk production, based on milk yield, milk composition, BW, and feed intake, using the NRC equations (National Research Council, 2001).

\section{Blood Collection}

Caudal blood samples were taken just before milk collection on d $-6,-2,-1,1,2,3,4,5,6,12$, and 19 in Vacutainer collection tubes without additives and in EDTA-coated Vacutainer tubes (BD, Mississauga, ON, Canada). The blood tubes without additives were left at room temperature for approximately $2 \mathrm{~h}$ to allow clotting before centrifugation $\left(1,900 \times g, 4^{\circ} \mathrm{C}, 15 \mathrm{~min}\right)$. Then, the serum was stored at $-20^{\circ} \mathrm{C}$ until determination of PRL, cortisol, urea, and serum amyloid A concentrations. The blood tubes containing EDTA were placed on ice immediately after collection and centrifuged $\left(1,900 \times g, 4^{\circ} \mathrm{C}, 15 \mathrm{~min}\right)$ within $30 \mathrm{~min}$. Then, the plasma was stored at $-20^{\circ} \mathrm{C}$ until determination of glucose, NEFA, BHB, lactose, and tumor necrosis factor $\alpha(\mathbf{T N F}-\alpha)$ concentrations.

Jugular blood samples were taken on $\mathrm{d}-6,1,2$, and 4 using Vacutainer collection tubes without additives (BD). The tubes were left at room temperature for approximately $2 \mathrm{~h}$ to allow clotting before centrifugation $\left(1,900 \times g, 4^{\circ} \mathrm{C}, 15 \mathrm{~min}\right)$. Then, the serum was stored at $-20^{\circ} \mathrm{C}$ until peripheral blood mononuclear 
cell (PBMC) proliferation assays were performed. Additional blood samples were taken on $\mathrm{d}-6,1,2$, and 4 using Vacutainer sodium heparin collection tubes and were kept at room temperature until PMN phagocytosis and oxidative burst assays were performed (within $5 \mathrm{~h}$ of blood collection). Vacutainer tubes coated with EDTA were also filled and sent to an independent laboratory (Faculté de médecine vétérinaire, Université de Montréal, St-Hyacinthe, QC, Canada) for complete blood counts. Because the jugular blood sampling on $\mathrm{d}$ 2 was added during the experiment after the first block of cows had been completed, complete blood counts and phagocytosis assays on $\mathrm{d} 2$ could be performed only for the second block (4 cows in each treatment group). Oxidative burst assays were performed only on samples collected from the second block.

\section{Hormone Concentrations}

Serum PRL concentration was measured by RIA as described by Bernier-Dodier et al. (2011). Bovine PRL, rabbit antiserum specific for bovine PRL, and goat anti-rabbit gammaglobulin were purchased from the National Hormone and Peptide Program (HarborUCLA Medical Center, Torrance, CA). The intra- and inter-assay coefficients of variation $(\mathbf{C V})$ were 4.5 and $4.8 \%$, respectively. Serum cortisol concentration was determined by ELISA using the Cortisol Parameter Assay Kit (R\&D Systems Inc., Minneapolis, MN) according to the manufacturer's instructions. The intra- and interassay CV were 5.8 and $4.6 \%$, respectively. Dexamethasone does not cross-react with this cortisol assay.

\section{Metabolite Concentrations}

Serum urea concentration was determined using the QuantiChrom urea assay kit (BioAssay Systems, Hayward, CA) according to the manufacturer's instructions. The intra- and interassay CV were 3.2 and $2.8 \%$, respectively. Plasma glucose concentration was determined as previously described (Loiselle et al., 2009) using a glucose assay kit (Sekisui Diagnostics P.E.I. Inc., Charlottetown, PE, Canada) with a modification of the glucose oxidase/peroxidase method described by Trinder (1969). The intra- and inter-assay CV were 1.9 and $1.3 \%$, respectively. Plasma NEFA and BHB concentrations were determined as described in Ollier et al. (2014) using NEFA-HR(2) reagents (Wako Diagnostics, Richmond, VA) and a BHB reagent set (Pointe Scientific Inc., Canton, MI), respectively. The intraand inter-assay CV were 3.8 and $4.0 \%$ for NEFA and $2.3 \%$ and $2.5 \%$ for BHB, respectively. Plasma lactose concentration was determined using a lactose assay kit
(Sigma-Aldrich, Oakville, ON, Canada) according to the manufacturer's instructions. The intra- and interassay CV were 2.4 and $12.3 \%$, respectively.

\section{PMN Phagocytosis Assays}

Just after blood collection, PMN concentration was determined using CountBright absolute counting beads for flow cytometry (Life Technologies Inc., Burlington, ON, Canada), a calibrated suspension of a known concentration of microspheres that fluoresce brightly across a wide range of wavelengths for excitation and emission. For absolute counts, a specific volume of the microsphere suspension is added to a specific volume of the sample, so that the ratio of sample volume to microsphere volume is known. Briefly, $4 \mathrm{~mL}$ of red blood cell lysing buffer (Sigma-Aldrich) was added to $500 \mu \mathrm{L}$ of heparinized whole-blood sample. After red blood cell lysis was completed, the sample was diluted in Hanks' balanced salt solution (HBSS; Wisent Inc., St-Bruno, QC, Canada) and centrifuged at $350 \times g$ for 8 min at $20^{\circ} \mathrm{C}$. The pellet was washed with HBSS, centrifuged at $350 \times g$ for $5 \mathrm{~min}$ at $20^{\circ} \mathrm{C}$, and then suspended in $500 \mu \mathrm{L}$ of HBSS. The cells were transferred into a flow cytometry tube, and precisely $25 \mu \mathrm{L}$ of counting beads was added. The mixture was then run on a FACSCanto II flow cytometer (BD Biosciences, Mississauga, ON, Canada). Counting beads were gated using a linear forward versus linear side scatter plot, and 1,500 bead events were acquired per sample. The number of events on the PMN gate was recorded, and PMN concentration in the whole-blood sample was calculated using the following equation: number of PMN events/number of bead events $\times$ number of beads in $25 \mu \mathrm{L}$ of microsphere suspension/volume of blood sample.

The phagocytic capacity of PMN was then evaluated by flow cytometry using pHrodo red Escherichia coli bioparticles (Life Technologies Inc.), which are non- or weakly fluorogenic when attached to the outer surface of the phagocyte but become highly fluorescent in the acidic environment of the phagosome upon internalization. For each experimental sample, 5 flow cytometry tubes were filled with $100 \mu \mathrm{L}$ of heparinized whole blood (which had been cooled beforehand on ice for 10 min) and $20 \mu \mathrm{L}$ of cold pHrodo red E. coli bioparticles. The bioparticle concentration was adjusted in HBSS for each experimental sample according to the PMN concentration that had been previously determined, to achieve a 25:1 ratio of bioparticles to PMN. Of those 5 tubes, 3 were incubated at $38.5^{\circ} \mathrm{C}$ for $30 \mathrm{~min}$, and the other 2 were left on ice as negative controls. Another negative control containing $100 \mu \mathrm{L}$ of heparinized whole blood but no bioparticles was incubated 
at $38.5^{\circ} \mathrm{C}$ for $30 \mathrm{~min}$. After incubation, all tubes were placed immediately into ice for a minimum of $5 \mathrm{~min}$ to stop phagocytosis. The red cells were then lysed at room temperature by adding $1 \mathrm{~mL}$ of red blood cell lysing buffer (Sigma-Aldrich). After dilution in HBSS, the cells were centrifuged at $350 \times g$ for 5 min at $4^{\circ} \mathrm{C}$. The pellet was washed with HBSS, centrifuged at 350 $\times g$ for $5 \mathrm{~min}$ at $4^{\circ} \mathrm{C}$, and then suspended in $500 \mu \mathrm{L}$ of BD FACSFlow sheath fluid (BD Biosciences) containing 1\% formaldehyde (BioShop Canada Inc., Burlington, ON, Canada). The samples were analyzed 1 to $3 \mathrm{~h}$ after the addition of the fixative, using a FACSCanto II flow cytometer (BD Biosciences) equipped with BD FACSDiva v8.0 software (BD Biosciences), and the percentage of phagocytic PMN was determined. The optimal ratio of bioparticles to PMN, time of incubation, and conditions of fixing were based on the results of preliminary assays. The detectors of the FACSCanto II flow cytometer were calibrated daily before each use with cytometer setup and tracking beads (BD Biosciences) to ensure day-to-day reproducibility.

\section{PMN Oxidative Burst Assays}

In parallel with the phagocytosis assays, 2 flow cytometry tubes were filled with $100 \mu \mathrm{L}$ of heparinized whole blood (which had been cooled beforehand on ice) to measure the oxidative burst activity of PMN. In each tube, $20 \mu \mathrm{L}$ of dihydrorhodamine 123 (Life Technologies Inc.), which fluoresces when it is oxidized by reactive oxygen species, was added at a final concentration of $100 \mu M$. After a 15 -min incubation at $38.5^{\circ} \mathrm{C}$, the tubes were placed immediately on ice for $5 \mathrm{~min}$. In the first tube, $20 \mu \mathrm{L}$ of phorbol 12-myristate 13-acetate (Sigma-Aldrich) was then added at a final concentration of $500 \mathrm{n} M$ to activate the oxidative burst of PMN, and $20 \mu \mathrm{L}$ of HBSS was added to the second tube as a negative control. After a 30 -min incubation at $38.5^{\circ} \mathrm{C}$, the tubes were placed immediately on ice for $5 \mathrm{~min}$ to stop cell activity. The red cells were then lysed at room temperature by adding $1 \mathrm{~mL}$ of red blood cell lysing buffer (Sigma-Aldrich). After dilution in HBSS, the cells were centrifuged at $350 \times g$ for $5 \mathrm{~min}$ at $4^{\circ} \mathrm{C}$. The pellet was washed with HBSS, centrifuged at $350 \times g$ for $5 \mathrm{~min}$ at $4^{\circ} \mathrm{C}$, and then suspended in $500 \mu \mathrm{L}$ of $\mathrm{BD}$ FACSFlow sheath fluid (BD Biosciences) containing $1 \%$ formaldehyde (BioShop Canada Inc.). The samples were analyzed 1 to $3 \mathrm{~h}$ after the addition of the fixative, using a FACSCanto II flow cytometer (BD Biosciences), and the percentage of PMN positive for oxidative burst was determined. Preliminary assays were performed to determine the optimal concentrations of dihydrorhodamine 123 and phorbol 12-myristate 13-acetate.

\section{Peripheral Blood Mononuclear Cell Proliferation Assays}

Peripheral blood mononuclear cells were isolated from the jugular blood of 3 healthy cows. The blood had been collected in Vacutainer sodium heparin collection tubes (BD) and was centrifuged at $1,000 \times g$ for 15 min at $18^{\circ} \mathrm{C}$. The buffy coat layer was diluted in PBS (Wisent Inc.) and then layered on Ficoll-Paque PLUS (GE Healthcare, Baie-d'Urfé, QC, Canada) before being centrifuged at $800 \times g$ for $35 \mathrm{~min}$ at $18^{\circ} \mathrm{C}$. The PBMC layer was washed twice with PBS, resuspended in red blood cell lysing buffer (Sigma-Aldrich) for 2 min, and then diluted in PBS. After centrifugation at $200 \times g$ for $8 \mathrm{~min}$ at $18^{\circ} \mathrm{C}$, the pellet was washed with PBS and centrifuged at $200 \times g$ for $8 \mathrm{~min}$ at $18^{\circ} \mathrm{C}$. The PBMC were suspended in PBS, and live cell concentration was determined using a Countess automated cell counter (Life Technologies Inc.) and the trypan blue dye exclusion technique. Then, the PBMC were labeled with $1 \mu M$ carboxyfluorescein diacetate succinimidyl ester using the CellTrace CFSE Cell Proliferation Kit (Life Technologies Inc.). To assess the effect of the serum from treated cows on PBMC proliferation, labeled PBMC suspended in RPMI 1640 supplemented with antimicrobial agents and l-Gln (Wisent Inc.) and with $7.5 \%$ decomplemented sera (by heating for $30 \mathrm{~min}$ at $56^{\circ} \mathrm{C}$ ) sampled on $\mathrm{d}-6,1,2$, or 4 from each cow were incubated in a 96 -well plate $\left(1 \times 10^{5}\right.$ cells per well $)$ at $38.5^{\circ} \mathrm{C}$ for $72 \mathrm{~h}$. For each serum tested, the PBMC of 3 wells were incubated with the $\mathrm{T}$ cell mitogen concanavalin A (Sigma-Aldrich) at $1 \mu \mathrm{g} / \mathrm{mL}$, and the PBMC of 3 wells were incubated without the mitogen as a negative control. After a 72-h incubation, proliferation was analyzed using the FACSCanto II flow cytometer (BD Biosciences). Preliminary assays were performed to determine the optimal concentration of cow serum, the number of PBMC per well, the concentration of concanavalin A to be used, and the time of incubation. This assay was performed 3 times for each serum, with 1 assay per healthy cow from which the PBMC had been isolated. A control-positive serum obtained by mixing sera from 4 healthy cows in late lactation and another obtained by mixing sera from 3 freshly calved cows were included in each plate to determine inter-assay variation.

\section{Inflammation Marker Concentrations}

Plasma TNF- $\alpha$ concentration was determined using the bovine TNF- $\alpha$ DuoSet ELISA kit (R\&D Systems Inc.) according to the manufacturer's instructions. The intra- and interassay CV were 6.0 and $14.1 \%$, respec- 
tively. Serum amyloid A concentration was determined using the Tridelta phase range SAA ELISA kit (Tridelta Development Ltd., Maynooth, Ireland) according to the manufacturer's instructions. The intra- and interassay CV were 7.5 and $11.4 \%$, respectively.

\section{Statistical Analysis}

Data were analyzed separately for the pre-feedrestriction period $(\mathbf{P R E}$ period, $\mathrm{d}<1$ ), the restriction period before the first injection (RESTR period, d 1), the injection period (INJ period, d 2 to 5), and the post-feed-restriction and injection period (POST period, $\mathrm{d}>5$ ) by ANOVA using the MIXED procedure in SAS (SAS Institute Inc., Cary, NC). Time was used as a repeated effect, and cow (treatment) was used as the subject. Before analysis, SCC was $\log _{10}$-transformed. Orthogonal contrasts were used to compare least squares means of the QN and control groups and of the DEX and control groups. The least squares means of the QN and DEX groups were compared using the Tukey-Kramer adjustment. Because we had data for complete blood counts and phagocytosis assays for the 2 blocks of cows on $\mathrm{d}-6,1$, and 4 but for only the second block on d 2, treatment effect was discussed only if we did not observe any overall block effect. The correlations between the blood concentration of metabolites and the percentages of phagocytic PMN, oxidative-burst-positive PMN, and proliferative PBMC were evaluated using the CORR procedure in SAS. Differences were considered statistically significant when $P<0.05$.

\section{RESULTS}

\section{DMI, BW, Milk Production and Composition, and Energy Balance}

During the PRE period and throughout the experiment, DMI was similar for the 3 groups of animals (data not shown). The cows lost $(P=0.01) \mathrm{BW}$ during the experiment, but the loss was not affected by treatment. Body weight averaged $705 \pm 15,719 \pm 16$, and $697 \pm$ $15 \mathrm{~kg}$ at the start and $694 \pm 15,718 \pm 16$, and $688 \pm$ $15 \mathrm{~kg}$ at the end of the experiment for the QN, DEX, and control groups, respectively.

Milk production was similar for the 3 groups before the start of the experiment ( $\mathrm{d}-16$ to -1 ; Figure 1 ). Feed restriction induced a decrease $(P<0.001)$ in milk production throughout the restriction period (RESTR and INJ periods taken together, d 1 to 5), regardless of treatment. However, this drop was greater in the QN and DEX cows than in the control cows on $d$ $2(-31.7 \%, P<0.001$, and $-23.5 \%, P=0.002$, for QN and DEX, respectively) and on $\mathrm{d} 3(-19.9 \%, P$ $=0.01$, and $-25.0 \%, P=0.006$, for $\mathrm{QN}$ and DEX, respectively). We observed no difference between the QN and DEX cows throughout the INJ period. During the POST period, milk production gradually increased $(P<0.001)$ and was again similar for the 3 groups of animals (d 6 to 20$)$ but was lower $(P<0.001)$ than milk production during the PRE period.

Milk fat, protein, and lactose contents (Figure 2) and yields (Supplemental Figure S1; http://dx.doi. org/10.3168/jds.2016-11711) were similar for the 3 groups of animals during the PRE period. During the

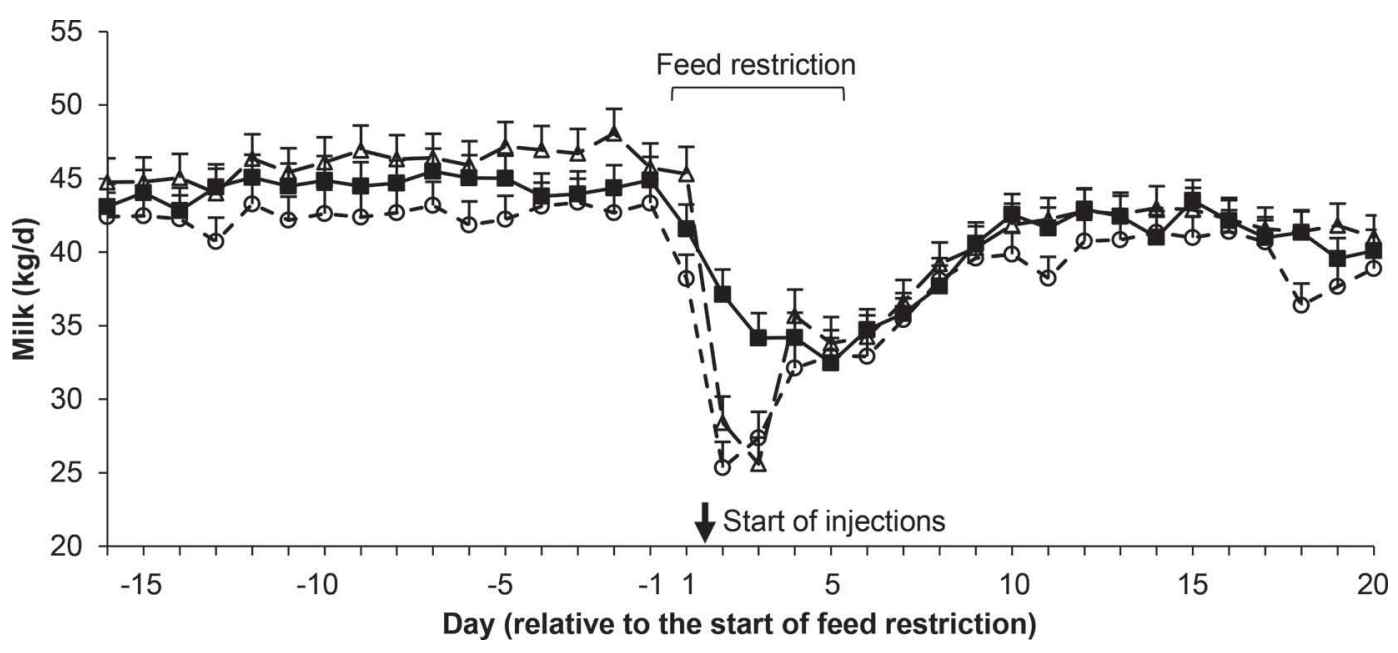

Figure 1. Milk production in cows that were feed-restricted for $5 \mathrm{~d}$ (d 1 to 5 ) and, after $1 \mathrm{~d}$ of feed restriction and for the remainder of the restriction period (d 2 to 5 ), injected twice daily with water (squares, solid line; $\mathrm{n}=8$ ), with 2 mg of quinagolide (circles, short-dashed line; $\mathrm{n}=7$ ), or with water after a first injection of $20 \mathrm{mg}$ of dexamethasone (triangles, long-dashed line; $\mathrm{n}=8$ ). Data presented are LSM \pm SEM. 
INJ period, we observed treatment $\times$ time interactions $(P<0.001)$ for milk fat content (Figure $2 \mathrm{~A})$ and yield (Supplemental Figure S1A). After $1 \mathrm{~d}$ of injections (on d 2), dexamethasone increased milk fat content and yield $(P<0.001)$ and quinagolide decreased milk fat content and yield $(P=0.05$ and $P<0.001$, respectively) compared with the control treatment. Fat content and yield were also lower $(P=0.04$ and $P=0.002$, respectively) in the milk of the QN cows than in that of the control cows on $\mathrm{d} 3$. Conversely, fat content and yield were greater $(P<0.001)$ in the milk of the QN cows than in that of the control and DEX cows on $\mathrm{d}$ 5. Moreover, fat content was greater $(P=0.03)$ in the milk of the QN cows than in that of the DEX cows during the POST period. During the INJ period, we observed treatment $\times$ time interactions $(P<0.001)$ for milk protein content (Figure 2B) and yield (Supplemental Figure S1B). Protein content was greater in the milk of the DEX cows than in that of the control cows $(P=0.001)$ and $\mathrm{QN}$ cows $(P=0.04)$ on $\mathrm{d} 2$. Protein yield was lower in the milk of the QN cows than in that of the control cows on $\mathrm{d} 2(P=0.001)$ and $\mathrm{d} 3$ $(P=0.02)$ and that of the DEX cows on $\mathrm{d} 2(P=$ $0.006)$. Protein yield was also lower in the milk of the DEX cows than in that of the control cows on $\mathrm{d} 3(P$ $<0.001)$. The treatments had no effect on milk protein content and yield during the POST period. During the INJ period, we observed treatment $\times$ time interactions for milk lactose content $(P<0.001$; Figure $2 \mathrm{C})$ and yield $(P=0.003$; Supplemental Figure S1C). Lactose content in the milk of the DEX cows was lower than that in the milk of the control cows $(P<0.001)$ and QN cows $(P<0.001)$ on $d 2$, but greater than that in the milk of the control cows $(P=0.006)$ on d 3. Lactose content in the milk of the QN cows was also greater than that in the milk of the control cows $(P=0.005)$ on $\mathrm{d} 3$, but similar to that in the milk of the DEX cows. Lactose yield was lower in the milk of the QN and DEX cows than in that of the control cows on $\mathrm{d} 2(P<0.001$ and $P=0.001$, respectively $)$ and $\mathrm{d} 3(P=0.05$ and $P$ $=0.02$, respectively). The treatments had no effect on milk lactose content and yield during the POST period. Throughout the experiment, SCC was similar for the 3 groups of animals (data not shown).

During the PRE period, calculated energy balance was similar for the 3 groups of animals $(-10.1 \pm 5.0$, $-4.5 \pm 6.1$, and $-5.4 \pm 5.7 \mathrm{MJ} / \mathrm{d}$ for the QN, DEX, and control groups, respectively). Feed restriction induced a drop $(P<0.001)$ in calculated energy balance throughout the restriction period (RESTR and INJ periods taken together, d 1 to 5), regardless of the treatment. However, during the INJ period, the drop in the $\mathrm{QN}$ cows $(-46.3 \pm 3.4 \mathrm{MJ} / \mathrm{d})$ was lower $(P=$
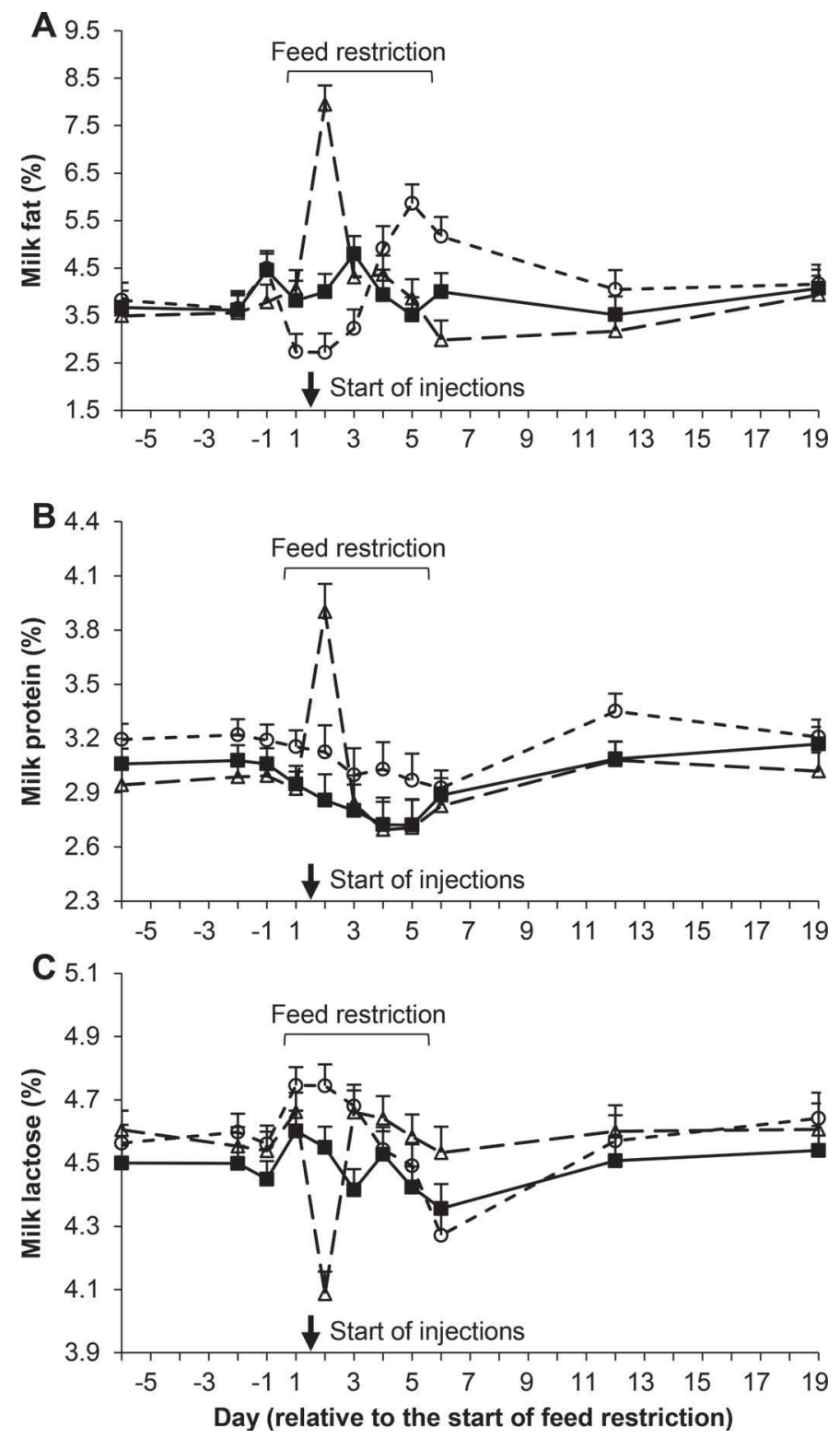

Figure 2. Milk fat (A), protein (B), and lactose (C) contents in cows that were feed-restricted for $5 \mathrm{~d}$ (d 1 to 5 ) and, after $1 \mathrm{~d}$ of feed restriction and for the remainder of the restriction period (d 2 to 5 ), injected twice daily with water (squares, solid line; $\mathrm{n}=8$ ), with $2 \mathrm{mg}$ of quinagolide (circles, short-dashed line; $\mathrm{n}=7$ ), or with water after a first injection of $20 \mathrm{mg}$ of dexamethasone (triangles, long-dashed line; $\mathrm{n}=8)$. Data presented are LSM \pm SEM.

0.02) than the decrease in the control cows was $(-58.9$ $\pm 4.1 \mathrm{MJ} / \mathrm{d})$ and tended to be lower $(P=0.09)$ than the decrease in the DEX cows was $(-56.2 \pm 4.2 \mathrm{MJ} / \mathrm{d})$. During the POST period, calculated energy balance increased $(P<0.001)$ and was again similar for the 3 groups of animals $(-7.0 \pm 7.6,6.6 \pm 9.2$, and -1.0 $\pm 8.6 \mathrm{MJ} / \mathrm{d}$ for the QN, DEX, and control groups, respectively). 


\section{Blood PRL and Cortisol Concentrations}

During the PRE period, we observed a treatment $\times$ time interaction $(P=0.01)$ for basal blood PRL concentration (Figure 3A). Blood PRL concentration was similar for the 3 groups of animals on $\mathrm{d}-6$ and -2 but greater in the control cows than in the QN cows $(P=0.03)$ and DEX cows $(P=0.003)$ on $\mathrm{d}-1$. During the RESTR period, blood PRL concentration decreased $(P<0.001)$ in all cows and was lower in the control cows than in the QN cows $(P=0.01)$ and DEX cows $(P=0.05)$. Throughout the INJ period, blood PRL concentration in the QN cows was lower than in the control cows $(P=0.01)$ and tended to be lower than in the DEX cows $(P=0.1)$. We observed no difference between the DEX and control cows during the INJ period. During the POST period, blood PRL concentration increased $(P<0.001)$ and was again similar for the 3 groups of animals (d 6 to 19).
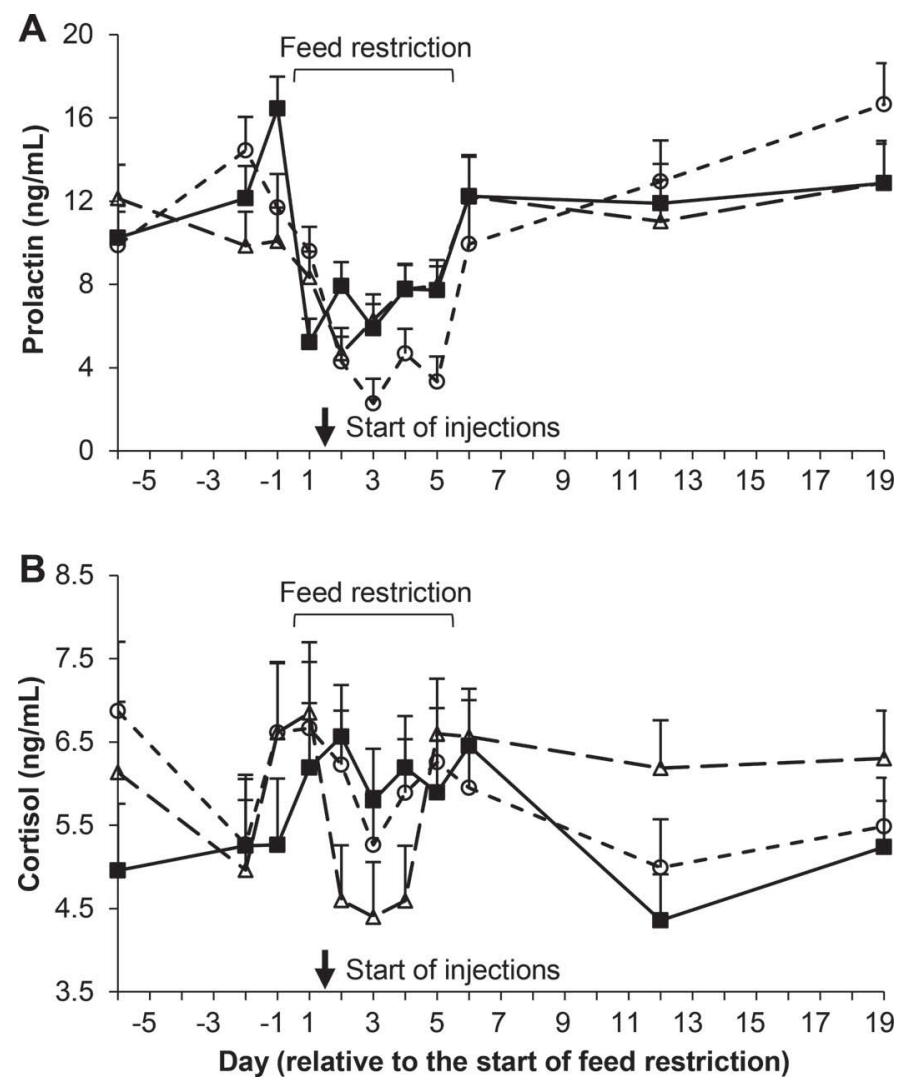

Figure 3. Blood concentrations of prolactin (A) and cortisol (B) in cows that were feed-restricted for $5 \mathrm{~d}$ (d 1 to 5 ) and, after $1 \mathrm{~d}$ of feed restriction and for the remainder of the restriction period (d 2 to 5), injected twice daily with water (squares, solid line; $\mathrm{n}=8$ ), with $2 \mathrm{mg}$ of quinagolide (circles, short-dashed line; $\mathrm{n}=7$ ), or with water after a first injection of $20 \mathrm{mg}$ of dexamethasone (triangles, long-dashed line; $\mathrm{n}=8)$. Data presented are LSM \pm SEM.
Blood cortisol concentration was similar for the 3 groups of animals during the PRE period (Figure 3B). The day after the beginning of feed restriction, we observed a general increase $(P=0.03)$ in blood cortisol concentration (on d 1 in comparison with the PRE period) that was similar for the 3 groups of cows. During the INJ period, we observed a treatment $\times$ time interaction $(P=0.05)$. Blood cortisol concentration was lower in the DEX cows than in the control cows on $\mathrm{d} 2$, 3 , and 4 ( $P<0.05$ for each day). We did not observe any difference between the QN and control groups or between the QN and DEX groups, with the exception that blood cortisol concentration tended to be lower $(P$ $=0.09)$ in the DEX cows than in the QN cows on $\mathrm{d} 4$. During the POST period, blood cortisol concentration was greater $(P=0.05)$ in the DEX cows than in the control cows, whereas we did not observe any difference between the QN and control groups or between the QN and DEX groups.

\section{Metabolic Marker Concentrations}

The effects of feed restriction and the injections on plasma glucose, NEFA, and BHB concentrations are presented in Figure 4. We did not observe any difference between the 3 groups of animals for these parameters during the PRE period.

During the INJ period, we observed a treatment $\times$ time interaction $(P<0.001)$ for plasma glucose concentration (Figure 4A). Glucose concentration was greater $(P<0.01)$ in blood of the $\mathrm{QN}$ cows than in that of the control cows on d 2 and 3 and tended to be lower $(P=0.1)$ on $\mathrm{d} 4$. Dexamethasone injection induced a sharp increase in blood glucose concentration, which was greater $(P<0.001)$ in the DEX cows than in the control and QN cows on d 2. However, glucose concentration in the blood of the DEX cows then quickly decreased and, on d 4 and 5, was similar to that of the control cows and lower $(P=0.02$ and $P=0.04$, on $\mathrm{d} 4$ and 5 respectively) than that of the QN cows. During the POST period, plasma glucose concentration was again similar for the 3 groups of animals.

Regardless of treatment, feed restriction induced a sharp increase $(P<0.001)$ in plasma NEFA concentration, which quickly decreased $(P<0.001)$ as soon as the cows were fed ad libitum (Figure $4 \mathrm{~B}$ ). During the INJ period, we observed a treatment $\times$ time interaction $(P=0.003)$. Plasma NEFA concentration was greater $(P<0.001)$ in the control cows than in the $\mathrm{QN}$ and DEX cows on $\mathrm{d} 2$, but we did not observe any difference between the QN and DEX cows throughout the INJ period. During the POST period, plasma NEFA concentration was again similar for the 3 groups. 
Regardless of treatment, feed restriction transiently decreased $(P<0.001)$ plasma BHB concentration on d 1 compared with the PRE period (Figure 4C). However, plasma BHB concentration in the control cows increased $(P=0.04)$ again from $\mathrm{d} 2$ such that it was greater than that in the $\mathrm{QN}$ cows $(P=0.03)$ and DEX cows $(P<0.001)$ throughout the INJ period, but we
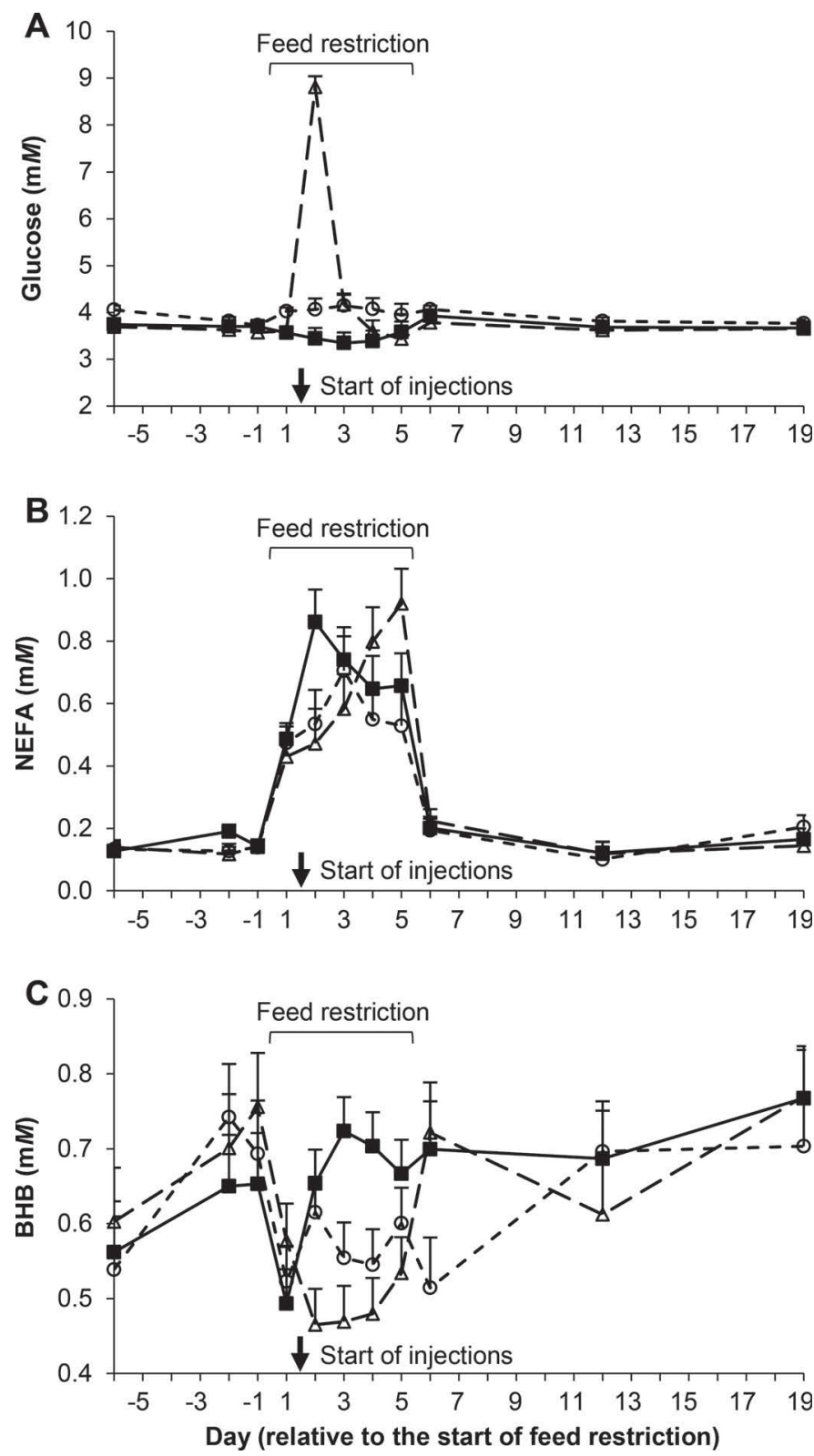

Figure 4. Blood concentrations of glucose (A), nonesterified fatty acids (NEFA; B), and BHB (C) in cows that were feed-restricted for $5 \mathrm{~d}(\mathrm{~d} 1$ to 5$)$ and, after $1 \mathrm{~d}$ of feed restriction and for the remainder of the restriction period (d 2 to 5), injected twice daily with water (squares, solid line; $\mathrm{n}=8$ ), with $2 \mathrm{mg}$ of quinagolide (circles, shortdashed line; $\mathrm{n}=7$ ), or with water after a first injection of $20 \mathrm{mg}$ of dexamethasone (triangles, long-dashed line; $\mathrm{n}=8$ ). Data presented are $\mathrm{LSM} \pm \mathrm{SEM}$ did not observe any difference between the QN and DEX cows. During the POST period, plasma BHB concentration was similar for the 3 groups of animals.

We did not observe any effect of the treatments on serum urea concentration during the experiment (data not shown). Lactose concentration in the blood of the DEX cows decreased $(P<0.001)$ on $\mathrm{d} 2$ then increased $(P=0.006)$ to reach a level similar to the concentration before the start of the experiment (data not shown).

\section{Immunological Parameters}

Complete blood counts were performed on $\mathrm{d}-6,1,2$, and 4 . We observed a treatment $\times$ time interaction $(P$ $<0.001$ ) for total white blood cell count (Figure 5A). Dexamethasone injection induced a sharp increase on d 2 in the number of total leukocytes, which was more than 2-fold greater in the blood of the DEX cows than in that of the control cows $(P=0.006)$ and the $\mathrm{QN}$ cows $(P=0.02)$. However, the number of total leukocytes in the blood of the DEX cows was again similar to that of the control and QN cows on d 4. This increase was concomitant with a large increase in the number of segmented neutrophils in the blood of the DEX cows $\left(12.20 \pm 0.56 \times 10^{9}\right.$ cells/L), which on d 2 was greater than that of the control cows $\left(2.73 \pm 0.54 \times 10^{9}\right.$ cells $/ \mathrm{L}$; $P=0.002)$ and $\mathrm{QN}$ cows $\left(3.79 \pm 0.54 \times 10^{9}\right.$ cells $/ \mathrm{L} ; P$ $=0.007)$. The treatments had no effect on the numbers of band neutrophils, eosinophils, basophils, monocytes, and lymphocytes (data not shown). We did not observe any difference in the numbers of total leukocytes and of each type of leukocyte between the QN and control cows before and during the experiment.

The phagocytosis and oxidative burst activities of PMN were evaluated in whole blood sampled on $\mathrm{d}-6$, 1,2 , and 4 (Figure 5B and C). The percentage of PMN positive for phagocytosis of pHrodo red E. coli bioparticles was similar for the 3 groups of animals on all sampling days (Figure 5B). We observed a treatment $x$ time interaction $(P=0.03)$ for the percentage of PMN stimulated with phorbol 12-myristate 13 -acetate that were positive for oxidative burst, which was lower in the DEX cows than in the control cows $(P=0.02)$ and QN cows $(P=0.04)$ on d 2 (Figure $5 \mathrm{C}$ ). This percentage was greater for PMN from the QN cows than for those from the control cows $(P=0.03)$ before the start of the experiment (on $d-6$ ) but was similar between these groups before the start of injections (on d 1) and during the INJ period on $\mathrm{d} 2$ and 4.

Peripheral blood mononuclear cells isolated from the blood of healthy cows were incubated with sera from QN, DEX, or control cows harvested on $\mathrm{d}-6,1,2$, and 4 to assess the effect of these sera on PBMC proliferation stimulated by concanavalin A (Figure 5D). The 
sera harvested on $\mathrm{d} 1$ decreased $(P<0.001)$ PBMC proliferation compared with the sera harvested before the start of experiment (on $\mathrm{d}-6$ ). The proliferation of PBMC was also lower $(P<0.001)$ with the sera harvested on $\mathrm{d} 2$ than with the sera harvested on $\mathrm{d} 1$, but PBMC proliferation with the sera harvested on $\mathrm{d} 4$ was higher $(P<0.001)$ and similar to the proliferation of PBMC incubated with the sera harvested on $\mathrm{d} 1$. However, we did not observe any difference between the sera from the QN, DEX, and control cows on any sampling day. We found an overall negative correlation between PBMC proliferation and blood NEFA concentration $(\mathrm{r}=-0.36, P<0.001)$, as well as a negative correlation between PBMC proliferation and blood BHB concentration on d $2(\mathrm{r}=-0.43, P=0.04)$.

Throughout the experiment, blood concentrations of the inflammation markers TNF- $\alpha$ and serum amyloid A were similar for the 3 groups of animals (data not shown).

\section{DISCUSSION}

Although feed restriction was applied abruptly, milk production declined gradually, such that the cows were in negative energy balance, as illustrated by changes in metabolite concentrations and estimated energy
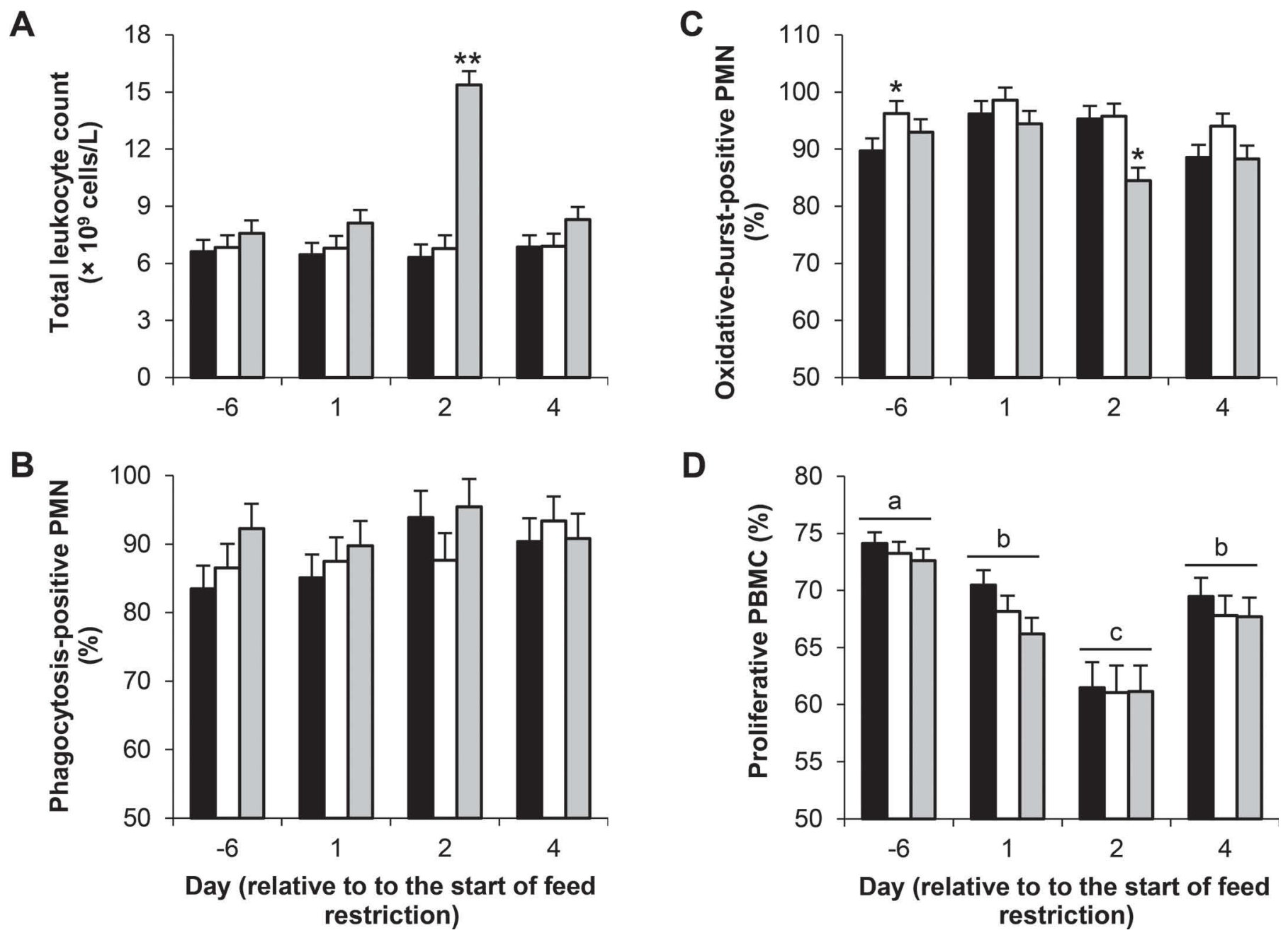

D

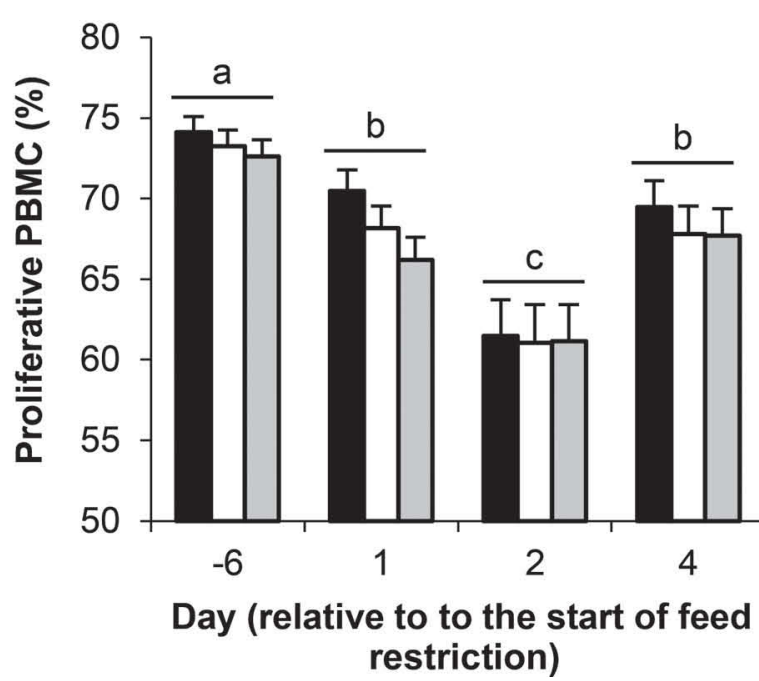

Figure 5. Total blood leukocytes (A), percentage of PMN positive for phagocytosis (B), percentage of PMN positive for oxidative burst (C), and percentage of proliferative peripheral blood mononuclear cells (PBMC; D) assayed from blood of cows that were feed-restricted for 5 $\mathrm{d}(\mathrm{d} 1$ to 5 ) and, after $1 \mathrm{~d}$ of feed restriction and for the remainder of the restriction period (d 2 to 5 ), injected twice daily with water (black bars; $\mathrm{n}=8$ ), with $2 \mathrm{mg}$ of quinagolide (white bars; $\mathrm{n}=7$ ), or with water after a first injection of $20 \mathrm{mg}$ of dexamethasone (gray bars; $\mathrm{n}=8$ ). The PBMC proliferation assay was conducted by measuring the effect of sera sampled on $\mathrm{d}-6,1,2$, and 4 on the percentage of proliferative concanavalin-A-stimulated PBMC isolated from healthy cows. All data presented are LSM $\pm \mathrm{SEM} ; *(P<0.05)$ and $* *(P<0.01)$ represent significant differences between the control and the dexamethasone or quinagolide treatments. Different letters indicate significant differences $(P$ $<0.001$ ) among sampling days, without a treatment effect. 
balance. The level of induced negative energy balance was not excessive, and none of the cows became ill. Nevertheless, milk production did not return to prerestriction levels. Therefore, we believe that the experimental model chosen was appropriate for simulating short-term nutritional stress.

A single injection of dexamethasone resulted in an abrupt, but transient, decrease in milk production. The milk-depressing effect of dexamethasone is well known (Hartmann and Kronfeld, 1973; Johke and Hodate, 1979; Shamay et al., 2000) and is related to its glucocorticoid properties, given that the administration of ACTH, which induces glucocorticoid secretion from adrenal glands, has a similar effect on milk yield (Campbell et al., 1964; Varner and Johnson, 1983). Several hypotheses have been proposed to explain the milk-depressing effect of glucocorticoids. The reduction in milk lactose concentration suggests the opening of mammary tight junctions. Indeed, inducing the opening of mammary tight junctions by intramammary infusion of EGTA reduces milk volume and milk concentration of lactose (Ben Chedly et al., 2010). Accordingly, Stelwagen et al. (2000) reported that cows selected for a high cortisol response to stress showed greater permeability of their tight junctions in response to isolation stress and to endotoxin-induced inflammation. However, the decrease in blood lactose concentration in the DEX cows after dexamethasone injection indicates not an opening of mammary tight junctions but instead, a decrease in their patency. Accordingly, ACTH injection decreases tight junction leakiness during an extended milking interval (Stelwagen et al., 1998). Another possibility is that glucocorticoids decrease lactose synthesis and thus milk volume, given that lactose is the main osmotic constituent of milk. Glucocorticoids decrease glucose uptake by skeletal muscle and adipose tissue by causing a state of insulin resistance (Kuo et al., 2015). Hartmann and Kronfeld (1973) reported that dexamethasone reduces glucose uptake by the mammary gland. Glucose uptake was not measured in the present experiment, but the transient hyperglycemia we observed suggests that dexamethasone reduced glucose uptake here as well.

Quinagolide reduced basal blood PRL concentration. Quinagolide is used in humans to treat hyperprolactinemia, and it binds specifically to the lactotroph dopamine D2 receptor, decreasing the synthesis and release of PRL (Brownell, 1996). Quinagolide injections caused a rapid reduction in milk production similar to that caused by dexamethasone. The milk-depressing effect of quinagolide has been observed in cows in early lactation (Lacasse et al., 2011) and late lactation (Ollier et al., 2013, 2014, 2015) and is likely the result of the inhibition of basal and milking-induced PRL release (Lacasse et al., 2016). Although PRL concentration remained low during the $4 \mathrm{~d}$ of treatment with quinagolide, milk production in the $\mathrm{QN}$ cows caught up to that of the control cows after $2 \mathrm{~d}$. In Ollier et al. (2013), our team also observed a partial rebound of milk production despite a low, but measurable, PRL concentration. This observation suggests that the mammary gland has the capacity to adapt its sensitivity to circulating PRL levels.

Feed restriction caused a reduction in basal blood PRL concentration. The reduction in the basal concentration of PRL in feed-restricted dairy cows has been reported previously (Vicini et al., 1988; Kuhla et al., 2010; Ollier et al., 2014, 2015). The fact that milk yield was also decreased in those studies raises the question of whether the reduction in PRL secretion plays a role in the inhibition of milk production. Nevertheless, maintaining high PRL concentration in feed-restricted cows with domperidone injections did not prevent a decline in milk production, although those cows produced more milk than cows receiving placebo injections (Lacasse and Ollier, 2015).

Feed restriction enhanced blood cortisol concentration. Moderate feed restriction did not previously affect plasma (Fisher et al., 2002) or milk (Gellrich et al., 2015) cortisol concentration in lactating dairy cows. However, feed deprivation has been shown to enhance the basal concentration of cortisol in young bulls (Ward et al., 1992) and lactating dairy cows (Samuelsson et al., 1996). Accordingly, Gross et al. (2015) reported that the basal concentration of cortisol is increased by the infusion of BHB and by hypoglycemia induced by insulin infusion. This finding suggests that metabolic perturbations associated with negative energy balance affect the hypothalamic-pituitary-adrenal axis.

Dexamethasone injection reduced cortisol concentration. Glucocorticoids exert feedback inhibition on their own secretion (Sapolsky et al., 1990). Accordingly, dexamethasone has been shown to inhibit corticosteroid secretion by blocking the effects of corticotropinreleasing hormone on the pituitary gland (Cole et al., 2000).

As expected, feed restriction induced a decrease in plasma glucose concentration and an increase in plasma NEFA concentration. Unexpectedly, BHB concentration declined on the first day of restriction, increased in the following days, and remained high during the refeeding period. Nielsen et al. (2003) reported that in cows fed at $65 \%$ of their previous week's ad libitum DMI, plasma and milk BHB concentrations remained constant on the first day of restriction and increased gradually on the following days. However, BHB con- 
centration undergoes diurnal variation, and the timings of peak and nadir values are influenced by time relative to meals and the level of energy intake (Nielsen et al., 2003; Meier et al., 2010). Although feeding and sampling times were not changed during the restriction period in our study, the length of time without feeds was longer during that period, and may have influenced the diurnal pattern of $\mathrm{BHB}$ variation. Accordingly, the milk BHB estimation provided by the DHI laboratory that ran the milk sample analyses showed the expected pattern, with low values before restriction and during the refeeding period and greater concentrations during the restriction period. Nevertheless, because the restriction was applied to all cows at the same time, the comparison of treatment effects within each day is valid.

Treating cows with quinagolide significantly reduced the changes in blood glucose, NEFA, and BHB concentrations due to feed restriction. Accordingly, greater blood glucose concentration was also observed in cows in positive energy balance treated with quinagolide compared with untreated cows (Ollier et al., 2014). Quinagolide injections enhanced energy balance, and this improvement is certainly a major factor driving improvement of the metabolic profile. Limiting milk production in early lactation by milking once a day (Loiselle et al., 2009; Kay et al., 2013) or partially (Carbonneau et al., 2012) also resulted in improvement of the metabolic profile. Overall, these results indicate that quinagolide can reduce the metabolic perturbation associated with nutritional stress.

In addition to the effect of dexamethasone on glucose discussed earlier, the injection of dexamethasone decreased blood BHB concentration but initially decreased and then later increased NEFA concentration. The effect on BHB was expected, given that dexamethasone was shown to decrease the concentration of ketone bodies in normal cows (Hartmann and Kronfeld, 1973) and ketotic cows (Andersson and Olsson, 1984). Few data are available on the effect of glucocorticoids on NEFA concentration. In a study, the injection of a glucocorticoid (isoflupredone) increased serum NEFA concentration in early postpartum cows (Seifi et al., 2007), whereas a similar, more recent study reported no effect of dexamethasone (Sami et al., 2015). The dexamethasone half-life in bovine plasma is between 5 and $6 \mathrm{~h}$ (Toutain et al., 1982; Gaignage et al., 1991). Fairclough et al. (1981) showed in dairy cows that the peak plasma concentration of dexamethasone occurred 2 to $20 \mathrm{~min}$ after the i.m. injection of $20 \mathrm{mg}$ of dexamethasone sodium phosphate. In that study, the plasma concentration of dexamethasone then declined sharply over the $24 \mathrm{~h}$ following treatment and was undetectable after $72 \mathrm{~h}$. The immediate metabolite response to dexamethasone injection is positive, but more than 1 injection might be necessary to maintain that response for more than $2 \mathrm{~d}$.

Feed restriction and quinagolide injections did not significantly affect the number and activity of PMN, whereas dexamethasone injection increased the total number of PMN in blood circulation but decreased the proportion of PMN capable of inducing oxidative burst after stimulation with phorbol 12-myristate 13-acetate. The anti-inflammatory and immunosuppressive actions of glucocorticoids are well known. The increase in the number of PMN in blood circulation is believed to be in part the result of impaired migration ability due to the downregulation of L-selectin and CD18 adhesion molecules on these cells (Burton et al., 1995). In addition, the increased release of neutrophils from bone marrow has been observed following the administration of corticosteroids (Roth et al., 1982). Dexamethasone has also been reported to impair the oxidative metabolism of bovine PMN, indicating that an important component of the neutrophil bactericidal mechanism in cattle is impaired by dexamethasone administration (Roth and Kaeberle, 1981, 1982). Although dexamethasone injection reduces milk production and metabolic perturbation, its immunosuppressive effects compromise these benefits during nutritional stress.

The incubation of PBMC in sera harvested on d 2 of the restriction period reduced the proliferation of these cells. Similarly, previous studies found that PBMC proliferation and IL-4 secretion decreased in response to incubation with sera from early postpartum cows (Carbonneau et al., 2012; Ster et al., 2012) or feed-restricted cows (Ollier et al., 2014). In those experiments, negative correlations were found between serum NEFA concentration and PBMC proliferation and between serum NEFA concentration and IL-4 secretion. Accordingly, we also found a negative correlation between PBMC proliferation and serum NEFA concentration. Ster et al. (2012) observed that serum harvested at 61 DIM, but supplemented with enough NEFA to reach the level present in serum harvested at 5 DIM, resulted in PBMC proliferation similar to that obtained with the latter serum, suggesting that circulating NEFA impair PBMC function. In the present study, neither the quinagolide nor the dexamethasone treatment affected PBMC proliferation. In previous studies, treatment effects were detected when differences in NEFA concentration were in the vicinity of $0.6 \mathrm{mM}$ (Carbonneau et al., 2012; Ster et al., 2012; Ollier et al., 2014). In the present study, differences in NEFA concentration between the $\mathrm{QN}, \mathrm{DEX}$, and control groups were around $0.3 \mathrm{mM}$ and were probably not large enough to noticeably affect lymphoproliferation. We therefore cannot exclude the 
possibility that quinagolide or dexamethasone might directly affect PBMC functions, but could not assess it with this experimental model.

In conclusion, inhibiting PRL release using quinagolide or injecting dexamethasone could be used to temporarily decrease milk production and improve the energy status of feed-restricted cows. However, the injection of dexamethasone disturbed the number and functions of PMN, whereas quinagolide treatment did not. Inhibiting the lactogenic signal using quinagolide might be an alternative for reducing milk production and energy deficit in cows under acute nutritional stress. Nevertheless, further research is required to determine whether this approach can reduce the incidence of metabolic and infectious diseases in these cows.

\section{ACKNOWLEDGMENTS}

The authors thank the following people (all from Agriculture and Agri-Food Canada, Sherbrooke, QC, Canada): Véronique Roy, Clémence Bitu, Marie-Pascale Morin, and Samuel Lanctôt for providing technical assistance; and the dairy barn staff for taking care of the cows. The authors are grateful to Mary Varcoe, from the Translation Bureau, Public Works, and Government Services Canada, for her careful editing of this manuscript. The authors also thank the National Hormone and Peptide Program and A. F. Parlow for providing the bovine prolactin and antibodies. This research was financially supported by Agriculture and Agri-Food Canada (Ottawa, ON, Canada) and by the Natural Sciences and Engineering Research Council of Canada (Ottawa, ON, Canada).

\section{REFERENCES}

Andersson, L., and T. Olsson. 1984. The effect of two glucocorticoids on plasma glucose and milk production in healthy cows and the therapeutic effect in ketosis. Nord. Vet. Med. 36:13-18.

Ben Chedly, H., M. Boutinaud, P. Bernier-Dodier, P. G. Marnet, and P. Lacasse. 2010. Disruption of cell junctions induces apoptosis and reduces synthetic activity in lactating goat mammary gland. J. Dairy Sci. 93:2938-2951.

Bernier-Dodier, P., C. L. Girard, B. G. Talbot, and P. Lacasse. 2011 Effect of dry period management on mammary gland function and its endocrine regulation in dairy cows. J. Dairy Sci. 94:4922-4936.

Braun, R. K., E. N. Bergman, and T. F. Albert. 1970. Effects of various synthetic glucocorticoids on milk production and blood glucose and ketone body concentrations in normal and ketotic cows. J. Am. Vet. Med. Assoc. 157:941-946.

Brownell, J. 1996. Quinagolide (Norprolac): A novel non-ergot prolactin inhibitor. Drugs Today (Barc) 32:1-31.

Burton, J. L., M. E. Kehrli Jr., S. Kapil, and R. L. Horst. 1995. Regulation of L-selectin and CD18 on bovine neutrophils by glucocorticoids: effects of cortisol and dexamethasone. J. Leukoc. Biol. $57: 317-325$.

Campbell, I. L., A. W. F. Davey, F. H. McDowall, G. F. Wilson, and R. E. Munford. 1964. The effect of adrenocorticotrophic hormone on the yield, composition and butterfat properties of cow's milk. J. Dairy Res. 31:71-79.

Canadian Council on Animal Care. 1993. Guide to the care and use of experimental animals. Vol. 1. 2nd ed. E. D. Olfert, B. M. Cross, and A. A. McWilliam, ed. CCAC, Ottawa, ON, Canada.

Carbonneau, E., A. M. de Passillé, J. Rushen, B. G. Talbot, and P. Lacasse. 2012. The effect of incomplete milking or nursing on milk production, blood metabolites, and immune functions of dairy cows. J. Dairy Sci. 95:6503-6512.

Chilliard, Y., F. Bocquier, and M. Doreau. 1998. Digestive and metabolic adaptations of ruminants to undernutrition, and consequences on reproduction. Reprod. Nutr. Dev. 38:131-152.

Cole, M. A., P. J. Kim, B. A. Kalman, and R. L. Spencer. 2000 Dexamethasone suppression of corticosteroid secretion: Evaluation of the site of action by receptor measures and functional studies. Psychoneuroendocrinology 25:151-167.

Fairclough, R. J., J. T. Hunter, and R. A. Welch. 1981. Dexamethasone concentrations in plasma and milk of cows following the injection of long- and short-acting dexamethasone esters. Aust. J. Biol. Sci. 34:313-319.

Fisher, A. D., G. A. Verkerk, C. J. Morrow, and L. R. Matthews 2002. The effects of feed restriction and lying deprivation on pituitary-adrenal axis regulation in lactating cows. Livest. Prod. Sci. 73:255-263.

Gaignage, P., G. Lognay, D. Bosson, D. Vertongen, P. Dreze, M. Marlier, and M. Severin. 1991. Dexamethasone bovine pharmacokinetics. Eur. J. Drug Metab. Pharmacokinet. 16:219-221.

Gellrich, K., T. Sigl, H. H. Meyer, and S. Wiedemann. 2015. Cortisol levels in skimmed milk during the first 22 weeks of lactation and response to short-term metabolic stress and lameness in dairy cows. J. Anim. Sci. Biotechnol. 6:31.

Goff, J. P. 2006. Major advances in our understanding of nutritional influences on bovine health. J. Dairy Sci. 89:1292-1301.

Gross, J. J., O. Wellnitz, and R. M. Bruckmaier. 2015. Cortisol secretion in response to metabolic and inflammatory challenges in dairy cows. J. Anim. Sci. 93:3395-3401.

Hartmann, P. E., and D. S. Kronfeld. 1973. Mammary blood flow and glucose uptake in lactating cows given dexamethasone. J. Dairy Sci. 56:896-902

Ingvartsen, K. L., and K. Moyes. 2013. Nutrition, immune function and health of dairy cattle. Animal 7(Suppl. 1):112-122.

Johke, T., and K. Hodate. 1979. Effects of dexamethasone on plasma hormone levels and milk production in the lactating cows with or without concomitant administration of thyrotropin releasing hormone, thyroxine, growth hormone, and prolactin. Endocrinol. Jpn. $26: 533-539$

Kay, J. K., C. V. C. Phyn, A. G. Rius, S. R. Morgan, T. M. Grala, and J. R. Roche. 2013. Once-daily milking during a feed deficit decreases milk production but improves energy status in early lactating grazing dairy cows. J. Dairy Sci. 96:6274-6284.

Kuhla, B., D. Albrecht, R. Bruckmaier, T. Viergutz, G. Nürnberg, and C. C. Metges. 2010. Proteome and radioimmunoassay analyses of pituitary hormones and proteins in response to feed restriction of dairy cows. Proteomics 10:4491-4500.

Kuo, T., A. McQueen, T.-C. Chen, and J.-C. Wang. 2015. Regulation of glucose homeostasis by glucocorticoids. Pages 99-126 in Glucocorticoid Signaling. Vol. 872. J.-C. Wang and C. Harris, ed. Springer, New York, NY.

Lacasse, P., V. Lollivier, R. M. Bruckmaier, Y. R. Boisclair, G. F Wagner, and M. Boutinaud. 2011. Effect of the prolactin-release inhibitor quinagolide on lactating dairy cows. J. Dairy Sci. 94:1302-1309

Lacasse, P., and S. Ollier. 2015. The dopamine antagonist domperidone increases prolactin concentration and enhances milk production in dairy cows. J. Dairy Sci. 98:7856-7864.

Lacasse, P., S. Ollier, V. Lollivier, and M. Boutinaud. 2016. New insights into the importance of prolactin in dairy ruminants. J. Dairy Sci. 99:864-874.

Loiselle, M. C., C. Ster, B. G. Talbot, X. Zhao, G. F. Wagner, Y. R. Boisclair, and P. Lacasse. 2009. Impact of postpartum milking 
frequency on the immune system and the blood metabolite concentration of dairy cows. J. Dairy Sci. 92:1900-1912.

Meier, S., E. S. Kolver, G. A. Verkerk, and J. R. Roche. 2010. Effects of divergent Holstein-Friesian strain and diet on diurnal patterns of plasma metabolites and hormones. J. Dairy Res. 77:432-437.

National Research Council. 2001. Nutrient Requirements of Dairy Cattle. 7th rev. ed. Natl. Acad. Press, Washington, DC.

Nielsen, N. I., K. L. Ingvartsen, and T. Larsen. 2003. Diurnal variation and the effect of feed restriction on plasma and milk metabolites in TMR-fed dairy cows. J. Vet. Med. A Physiol. Pathol. Clin. Med. 50:88-97.

Ollier, S., X. Zhao, and P. Lacasse. 2013. Effect of prolactin-release inhibition on milk production and mammary gland involution at drying-off in cows. J. Dairy Sci. 96:335-343.

Ollier, S., X. Zhao, and P. Lacasse. 2014. Effects of feed restriction and prolactin-release inhibition at drying off on metabolism and mammary gland involution in cows. J. Dairy Sci. 97:4942-4954.

Ollier, S., X. Zhao, and P. Lacasse. 2015. Effects of feed restriction and prolactin-release inhibition at drying-off on susceptibility to new intramammary infection in cows. J. Dairy Sci. 98:221-228.

Roth, J. A., and M. L. Kaeberle. 1981. Effects of in vivo dexamethasone administration on in vitro bovine polymorphonuclear leukocyte function. Infect. Immun. 33:434-441.

Roth, J. A., and M. L. Kaeberle. 1982. Effect of glucocorticoids on the bovine immune system. J. Am. Vet. Med. Assoc. 180:894-901.

Roth, J. A., M. L. Kaeberle, and W. H. Hsu. 1982. Effects of ACTH administration on bovine polymorphonuclear leukocyte function and lymphocyte blastogenesis. Am. J. Vet. Res. 43:412-416.

Sami, M., M. Mohri, and H. A. Seifi. 2015. Effects of dexamethasone and insulin alone or in combination on energy and protein metabolism indicators and milk production in dairy cows in early lactation - A randomized controlled trial. PLoS One 10:e0139276.

Samuelsson, B., K. Uvnäs-Moberg, R. C. Gorewit, and K. Svennersten-Sjaunja. 1996. Profiles of the hormones somatostatin, gastrin, CCK, prolactin, growth hormone, oxytocin and cortisol. II. In dairy cows that are milked during food deprivation. Livest. Prod. Sci. 46:57-64.

Sapolsky, R. M., M. P. Armanini, D. R. Packan, S. W. Sutton, and P. M. Plotsky. 1990. Glucocorticoid feedback inhibition of adrenocorticotropic hormone secretagogue release. Relationship to corticosteroid receptor occupancy in various limbic sites. Neuroendocrinology 51:328-336.
Seifi, H. A., S. J. LeBlanc, E. Vernooy, K. E. Leslie, and T. F. Duffield. 2007. Effect of isoflupredone acetate with or without insulin on energy metabolism, reproduction, milk production, and health in dairy cows in early lactation. J. Dairy Sci. 90:4181-4191.

Shamay, A., F. Shapiro, H. Barash, I. Bruckental, and N. Silanikove. 2000. Effect of dexamethasone on milk yield and composition in dairy cows. Ann. Zootech. 49:343-352.

Sheldon, I. M. 2004. The postpartum uterus. Vet. Clin. North Am. Food Anim. Pract. 20:569-591.

Stelwagen, K., H. Hopster, J. T. N. Van Der Werf, and H. J. Blokhuis. 2000. Short communication: Effects of isolation stress on mammary tight junctions in lactating dairy cows. J. Dairy Sci. 83:48-51.

Stelwagen, K., D. C. van Espen, G. A. Verkerk, H. A. McFadden, and V. C. Farr. 1998. Elevated plasma cortisol reduces permeability of mammary tight junctions in the lactating bovine mammary epithelium. J. Endocrinol. 159:173-178.

Ster, C., M. C. Loiselle, and P. Lacasse. 2012. Effect of postcalving serum nonesterified fatty acids concentration on the functionality of bovine immune cells. J. Dairy Sci. 95:708-717.

Suriyasathaporn, W.. C. Heuer, E. N. Noordhuizen-Stassen, and Y. H. Schukken. 2000. Hyperketonemia and the impairment of udder defense: A review. Vet. Res. 31:397-412.

Toutain, P. L., R. A. Brandon, M. Alvinerie, R. Garcia-Villar, and Y. Ruckebusch. 1982. Dexamethasone in cattle: Pharmacokinetics and action on the adrenal gland. J. Vet. Pharmacol. Ther. 5:33-43.

Trinder, P. 1969. Determination of glucose in blood using glucose oxidase with an alternative oxygen acceptor. Ann. Clin. Biochem. 6:24-27.

van der Kolk, J. H. 1990. The bovine pituitary-adrenocortical axis and milk yield. Vet. Q. 12:114-120.

Varner, M. A., and B. H. Johnson. 1983. Influence of adrenocorticotropin upon milk production, milk constituents, and endocrine measures of dairy cows. J. Dairy Sci. 66:458-465.

Vicini, J. L., W. S. Cohick, J. H. Clark, S. N. McCutcheon, and D. E. Bauman. 1988. Effects of feed intake and sodium bicarbonate on milk production and concentrations of hormones and metabolites in plasma of cows. J. Dairy Sci. 71:1232-1238.

Ward, J. R., D. M. Henricks, T. C. Jenkins, and W. C. Bridges. 1992. Serum hormone and metabolite concentrations in fasted young bulls and steers. Domest. Anim. Endocrinol. 9:97-103. 